\section{THE TREATMENT OF RHEUMATISM IN GENERAL PRACTICE.}

By W. S. C. Copeman. Edward Arnold \& Co. 2nd Edition. 1935. 9/- net.

Dr. Copeman is to be congratulated on the second edition of his book which follows within two years of the first edition. In many ways the second . edition is a considerable improvement. The book is now divided into two main sections, the first dealing with the various forms of rheumatism from a clinical and therapeutic standpoint. The second details the methods of application and the uses of physical methods of treatment, including the use of endocrines, baths, manipulative measures, with a brief résumé of spa treatment.

Without being in any way too scientific, Dr. Copeman has made his book essentially readable and practical, and if only for this alone it can be strongly recommended as a most useful guide which represents the various modes of treatment in use in this country.

\section{UROLOGY IN GENERAL PRACTICE. (General Practice Series)}

By Alex E. Roche, M.A., M.D., M.Ch. (Camb.), F.R.C.S. (Eng.). H. K. Lewis $\&$ Co. Ltd. $+\times 356$ pages, 3 coloured plates and 40 text figures. 1935. Price $17 / 6$ net.

This book has been essentially written to give the general practitioner an account of common genito-urinary diseases and modern methods of diagnosis and treatment. The author has wisely left out details of operative technique and has only indicated the general lines of operative treatment. For practitioners who have not been in touch with modern urological work this book should prove extremely useful.

It commences with an account of the examination of a urological patient and is followed by chapters on such general symptoms as frequency, incontinence, painful and difficult micturition, retention, suppression, hæmaturia and pyuria. Thereafter the common diseases of the kidney, bladder and genitals are described, and their symptoms, diagnosis and treatment discussed. Preceding the chapters on the kidney there is an excellent account of pyelography and its uses, and at the commencement of the section on the bladder there is a chapter on cystoscopy.

There is an interesting chapter on cystitis in which the importance of a full urological examination is emphasized. Enlargement of the prostate is adequately considered, and there is a useful account of catheters and catheterization. The author has purposely given most space and detail not to the more important conditions, but rather to those that are likely to be less well known, and are not to be found in the ordinary text-books-thus he devotes 25 pages to "tortion of the spermatic cord" and 10 pages to "tortion of the hydatid of Morgagni." His account of these conditions is very full and complete, and they would appear to be much commoner than might be generally supposed.

We note that in retention which cannot be relieved by catheter or where suprapubic drainage of the bladder is required the author is averse to puncture of the bladder, and prefers a cystostomy on grounds of safety. The method of puncture with a trocar and cannula and the insertion of a de Pezzer catheter is now so widely used that some account of it, and of the method of withdrawing and inserting a new catheter might have been useful. The final chapter on recent advances in urological treatment gives a very fair and useful account of these newer methods.

Throughout the book the opinions of urological authorities are freely quoted and there are a considerable number of references at the end of most chapters. There is a good index which is very essential in a work of this kind. The whole book is well got up and the illustrations and reproductions of X-ray photographs are excellent. We feel sure this book will amply fulfil the purpose for which it was written, and will be a useful addition to the library of any practitioner. 